rate after sterilisation. This can be further reduced if the operation is performed by experienced operators, if more of the tube is destroyed, if combined procedures with termination of pregnancy are avoided, and if operators are prepared to go ahead with laparotomy when circumstances are not ideal for laparoscopy.

\section{References}

${ }^{1}$ Hughes, G, and Liston, W A, British Medical fournal, 1975, 3, 637.

2 Thompson, B H, and Wheeless, C R, Obstetrics and Gynecology, 1975, 45,659 .
${ }^{3}$ Murdoch, R, Fournal of Obstetrics and Gynaecology of the British Commonwealth, 1969, 76, 1043 .

${ }^{4}$ Metz, K G, Fertility and Sterility, 1977, 25, 66.

5 Prystowsky, H, and Eastman, N, Fournal of the American Medical Association, 1955, 158, 463.

6 Cunanan jun, R G, and Courey, N G, Fournal of Reproductive Medicine, $1974,13,204$

' Steptoe, P C, British Medical fournal, 1975, 2, 138.

${ }^{8}$ Wheeless, C R, Clinical Obstetrics and Gynecology, 1976, 19, 282.

${ }^{9}$ Liston, W A, et al, Lancet, 1970, 1, 302.

"Chakravarti, S, and Sharolow, J, British fournal of Obstetrics and Gynaecology, 1975, 82, 58.

11 Wacek, A, and Glatthaar, E, Zentralblatt für Gynäkologie, 1965, 87, 821.

(Accepted 3 ()ctober 1977)

\title{
The National Poisons Information Service and hospital admissions for children-the experience in Wales of the Cardiff Centre
}

\author{
J D P GRAHAM, R A N HITCHENS
}

British Medical fournal, 1977, 2, 1339-1340

\section{Summary}

When inquiries to the Cardiff Centre of the National Poisons Information Service were compared with hospital admissions in the eight health authorities in Wales the findings suggested fewer admissions in the area within which the centre is situated and showed a more extensive use in that area than elsewhere. High inquiry rates were associated with high hospital admission rates when the eight areas were compared. If the service were delegated to area level a more complete community use would result.

\section{Introduction}

Admissions for acute poisoning continue to increase ${ }^{1-4}$ even though high-risk groups have been identified ${ }^{5}$ and methods of primary prevention suggested. Less attention has been directed to providing alternative ways of dealing with the problem. We analysed recent data from the Cardiff Centre of the National Poisons Information Service to determine whether the service had prevented unnecessary admissions in the health authority in which the centre is situated and in Wales as a whole. The purpose was to consider preventing unnecessary admissions, reducing costs, and finding the most appropriate organisation to do this.

We focused on children in the age group 0-14, who were the

Welsh National School of Medicine, Cardiff CF4 4XN

J D P GRAHAM, MD, FRCP, professor of pharmacology

R A N HITCHENS, MD, MFCM, senior lecturer in community medicine subject of $64^{\circ}{ }^{\circ}$ of inquiries to the Cardiff centre in 1975 . The suicidal motivation is largely eliminated; children have a greater tendency than adults to poison themselves with nonmedicinal substances, for which the National Poisons Information Service (NPIS) is specially equipped to offer help, and the increase in their hospital admissions over the years has been much the same order as in adults. ${ }^{\circ}$

\section{Materials and methods}

Sources of information for 1975 were the records of the Cardiff centre of the NPIS; the hospitals in South Glamorgan to which poisoning emergencies are normally admitted; and hospital activity analysis (HAA) data on discharges from hospitals in each of the eight area health authorities (AHA) in Wales. We looked for evidence of fewer admissions than requests to the NPIS for defined groups of substances in South Glamorgan, and compared request rates with hospital discharge rates for the eight AHAs.

In the Cardiff centre, each call is recorded with the date; name and address of the caller; telephone number, name, age, and sex of the patient; and the substance leading to the inquiry. Substances were classified under six headings (table I). The same classification was used for hospital admissions.

\section{Results and comment}

There were 248 calls about patients living in the emergency catchment area of the hospitals and 405 admissions for poisoning with an identified substance. The age and sex distributions of the two groups were almost identical, with more than $80 \%$ aged $0-4$, usually boys, and the modal age 2-3. Table I shows the groups classified by causal agent, and these differed greatly. Fifty-six per cent of inquiries compared with $20 \%$ of admissions concerned non-medical substances, the excess being not only proportionate but absolute (column 3 of table I).

Scrutiny of the drugs showed little difference between the two groups. In both some drugs had clearly been intended for the child, but most for adult members of the household; in some cases there 
TABLE I-Telephone inquiries and hospital admissions in catchment area of South Glamorgan hospitals compared for patients aged 0-14 by type of substance, 1975

\begin{tabular}{|c|c|c|c|}
\hline Substance & $\begin{array}{c}\text { No of } \\
\text { inquiries }\end{array}$ & $\begin{array}{l}\text { No of } \\
\text { admissions }\end{array}$ & $\begin{array}{c}\text { No of } \\
\text { admissions } \\
\text { possibly } \\
\text { prevented }\end{array}$ \\
\hline $\begin{array}{l}\text { Drugs } \\
\text { Non-medical substances } \\
\text { Household substances } \\
\text { Agricultural substances } \\
\text { Plants .. .. } \\
\text { Industrial chemicals } \ldots \\
\text { Toiletries } \ldots\end{array}$ & $\begin{aligned} & 110\left(44{ }^{\prime \prime}\left({ }_{1}\right)\right. \\
& 138\left(56{ }^{\prime \prime \prime)}\right. \\
67 & \\
19 & \\
20 & \\
5 & \\
27 & \end{aligned}$ & $\begin{array}{rr} & 325\left(80{ }^{\prime \prime}{ }^{\prime}\right) \\
37 & 80\left(2{ }^{\prime \prime}{ }^{\prime}\right) \\
17 & \\
19 & \\
2 & \\
5 & \end{array}$ & $\begin{array}{rr}30 & 58 \\
2 & \\
1 & \\
3 & \\
22 & \end{array}$ \\
\hline
\end{tabular}

Difference between drugs and total non-medicinal substances in columns 2 and 3: $\chi^{2}=89 \cdot 0$ for $1 \mathrm{DF} ; \mathrm{P}<0.001$.

was doubt. Salicylates, usually as "junior" aspirin, were the largest single component of the first category and benzodiazepines were prominent in the second.

Data derived from the HAA (table II) do not include cases admitted to hospitals in England (the latter is an important reservation, particularly for Powys, which lacks a district general hospital). The eight areas were ranked according to their usage of the Cardiff NPIS. Generally the inquiry rate declined as the distance from Cardiff increased. The four AHAs with highest inquiry rates had the highest discharge rates; among the four lowest NPIS users there was no clear pattern. The top four areas are the most densely populated and heavily industrialised in Wales. General practitioners (and a few other community workers), but not hospitals, made significantly more use of the NPIS in South Glamorgan than in other areas (table III).

TABLE II-Comparison of inquiries to NPIS and hospital discharge rates by area for poisoning per 10000 at ages $0-14$ in 1975

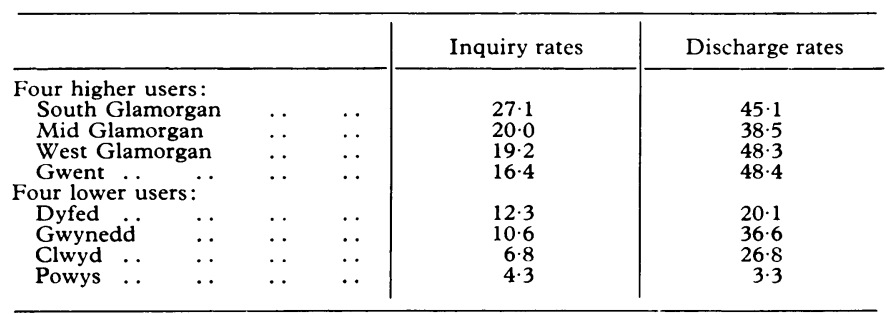

TABLE III-Telephone inquiries to NPIS in catchment area of S Glamorgan hospitals compared with all other areas in Wales by source of inquiry, and expected figures if service were evenly spread according to distribution of children aged 0-14 in Wales

\begin{tabular}{|c|c|c|c|c|}
\hline & \multicolumn{2}{|c|}{ Community } & \multicolumn{2}{|c|}{ Hospital } \\
\hline & Actual & Expected & Actual & Expected \\
\hline $\begin{array}{l}\text { South Glamorgan catchment area } \\
\text { Remainder of Wales ... }\end{array}$ & $\begin{array}{r}105 \\
90\end{array}$ & $\begin{array}{r}34 \\
161\end{array}$ & $\begin{array}{l}143 \\
704\end{array}$ & $\begin{array}{l}148 \\
699\end{array}$ \\
\hline Total & 195 & 195 & 847 & 847 \\
\hline
\end{tabular}

Difference for use by community $\mathrm{P}<0.001$. Difference for use by hospitals not significant.

\section{Discussion}

The National Poisons Information Service was established with the object not of preventing unnecessary hospital admission but rather of helping in the care of poisoned patients. ${ }^{7}$ Demands on the service have increased over the years and, although the frequency of hospital admissions has also increased, it might have been thought that easily available information would have reduced the rate of admissions, at least for children.

Data from South Glamorgan were consistent with the prevention of some admissions. If all 58 of the excess of inquiries over admissions were due to the intervention of the NPIS there would oe a saving of $£ 3000$ during the year, given a mean duration of stay of 1.5 days in hospitals where the cost per inpatient week was $£ 242$. The cost of the telephone calls is the only item to be set against this since staff operating the service are primarily engaged on other duties. Alternatively, the benefit could be measured in the release of beds and the saving in disturbance to patients and their parents.

When the eight AHAs in Wales were compared the HAA data indicated that more potent factors determine rates of hospital admissions. True incidence rates may be higher in urban and industrial areas and easy access to hospitals and awareness of other available services may encourage the use of both. Simple explanations of this kind, however, can scarcely explain the wide variation of hospital discharge rates shown by the lower four areas (table II).

We concluded that the NPIS has a useful if limited function in reducing hospital admissions, mainly exerted within the area close to the centre. If the service were reorganised so as to bring advice closer to those who need it by delegating it to area level it would be more systematically used by general practitioners and others in the community. The feasibility of reorganisation, the objectives of the NPIS, and finance must all be considered. Not every AHA may have the manpower available and willing to provide a 24 -hour service. But given these resources, would the additional expense be offset by a saving on hospital admissions? Before one could be confident of this, the NPIS would need to be more specifically designed for prevention than it is at present, which would require an extension of consultant services. A limited scheme might be justified by aiming exclusively at poisoning in children but most admissions for poisoning and drug misuse occur in adults.

If a poisons information centre were linked to one or more day centres in one AHA for patients not needing the full facilities of a regional hospital, hospital admission rates for poisoning could then be compared with rates in comparable AHAs with similar initial poisoning admission rates not having such facilities. It might then be possible to determine whether special managements ${ }^{*}$ affected standards of care or expense or both.

We are grateful to Mr P Samuel, Department of Medical Statistics, Welsh National School of Medicine, for assistance with the analysis.

\section{References}

${ }^{1}$ Jones, D I R, British Medical fournal, 1977, 1, 28.

2 Smith, A J, British Medical fournal, 1972, 4, 157.

${ }^{3}$ Alderson, M R, Lancet, 1974, 1, 1040.

4 Lawson, A H, and Mitchell, I, British Medical fournal, 1972, 4, 153.

${ }^{5}$ Kessel, N, British Medical fournal, 1965, 2, 1265.

- Department of Health and Social Security and Office of Population, Censuses, and Statistics, Hospital Inpatient Enquiry, 1967-73, serial vols. London, HMSO, 1970-7.

' Goulding, R, Monthly Bulletin of the Ministry of Health and Public Health Laboratory Service, 1965, 24, 26.

${ }^{8}$ Kennedy, P, British .Medical fournal, 1972, 4, 255.

(Accepted 3 October 1977)

Have any reactions been recorded after oral polio vaccination in adults, and do they induce rigor and diarrhoea, which occurred in a nurse 48 hours after the vaccine?

Oral polio vaccination has proved to be extremely safe, and very few side effects have been reported. As this is a live vaccine and produces an enteric infection, a mild bowel disturbance has occasionally been reported, but it is extremely unlikely that the vaccine caused a rigor 48 hours after the oral vaccine was administered. The Committee on Safety of Medicines have reports of rashes, urticaria, convulsions, encephalopathy, and vomiting, but sometimes the patients had already been receiving other medicaments when vaccinated, and a cause-andeffect relationship has not been established. Vaccine-related paralysis is believed to occur on rare occasions in contacts of vaccinated individuals, and this is why it is advisable to treat the whole family with oral vaccine at the same time. 